\title{
The concept of a passive heat transport system from solar collectors
}

\author{
Daniel Chludziński ${ }^{1,}{ }^{*}$, Michat Duda ${ }^{1}$, Piotr Sołowiej ${ }^{1}$, Joann Hałacz ${ }^{1}$ and Andrzej Lnage ${ }^{1}$ \\ ${ }^{1}$ University of Warmia and Mazury in Olsztyn, Department of Electrical Engineering, Power \\ Engineering, Electronics and Automation, Oczapowskiego 11, 10-736 Olsztyn, Poland
}

\begin{abstract}
The paper presents a concept of building a passive heat transport system based on the use of an antigravity thermosyphon with a bubble pump. Such solutions are suggested when the heat source is located above the place of its reception, e.g. in the case of solar collector installations. One of the components of the system is the device forcing the circulation of the heating medium. In the presented system, this process is carried out without the use of additional external sources of energy, such as electricity, to supply the circulating pumps. Such an installation is autonomous, so the risk of failure is diminished. It is also possible to automatically adjust the system to changing operating conditions without the need for additional automation. Other known solutions of this type are not used due to their imperfection. The challenge is to select the right working medium, whose physical properties should on the one hand transmit as much heat as possible, and on the other hand enable the pumping of the heating medium to be performed with low energy consumption. In the opinion of the authors of the paper, it is possible to achieve with the use of two working media in one system: water and a substance with a low boiling point.
\end{abstract}

\section{Introduction}

Rapid technological development spurs the search for new solutions to improve the performance and reliability of equipment. The demand for energy is directly linked with economic growth, and most of the energy consumed world-wide is derived from fossil fuels [1].

Thermal energy plays a considerable role in the economy, which is why heat transfer processes deserve special attention in a critical approach. Novel solutions should be characterized by the lowest possible energy consumption, sound and reliable design, low cost and low environmental impact.

Conventional heat exchange systems rely on hydraulic circuits with natural (thermosiphon) and forced circulation (electrical pump). From the point of view of energy conservation, passive systems (thermosiphons) are preferred because they do not require an external power source (electricity). They are also characterized by simple design and high

\footnotetext{
* Corresponding author: daniel.chludzinski@uwm.edu.pl
} 
reliability. Despite many advantages, passive heat exchange systems have a major drawback: heat is transferred in one direction only - from the bottom to the top of the tank.

Passive circulation systems that transport heat downward from the storage tank have been described in the literature [2, 3, 4]. Two-phase thermosiphons are one of such solutions. In two-phase thermosiphons, the temperature of the working medium reaches boiling point, and heat energy is transmitted by vapor. The main drawback of this solution is that the condensate has to be returned to the heating zone against the force of gravity. Condensate is lifted by the difference in vapor pressure between heat supply and heat extraction zones. Some systems feature porous materials to lift the condensate by capillary force. However, in such solutions, heat can be transferred only across small distances (several meters) [5].

A two-phase thermosiphon with a liquid heat exchanger supports passive downward transport of heat across greater distances. In this solution, condensate does not have to be lifted. These types of thermosiphons have been widely studied $[3,6,7,8,9$, 10]. Most of them rely on a single working medium, usually water or coolant. In water-based thermosiphons, negative pressure is produced when the temperature of the heat source falls below $100^{\circ} \mathrm{C}$, which creates practical problems. Vast amounts of coolant are needed to fill the entire system, which increases cost and exerts a negative impact on the environment. These types of systems are not widely used due to the problems associated with the selection of the optimal working medium.

This article presents the results of an experiment where two working media were applied to induce passive downward transfer of heat in a system with a low-temperature heat source. Unlike thermosiphons that operate cyclically [11, 12], the proposed system is characterized by continuous operation. The liquid medium is water, and the second medium is a substance with a low boiling point.

\section{A review of passive heat transfer systems}

Passive heat exchange systems generally rely on three physical phenomena: phase change, capillary flow and gravity. Depending on the structure of a passive heat exchange system, these phenomena can occur simultaneously, separately or in different combinations (Fig. 1) [13].

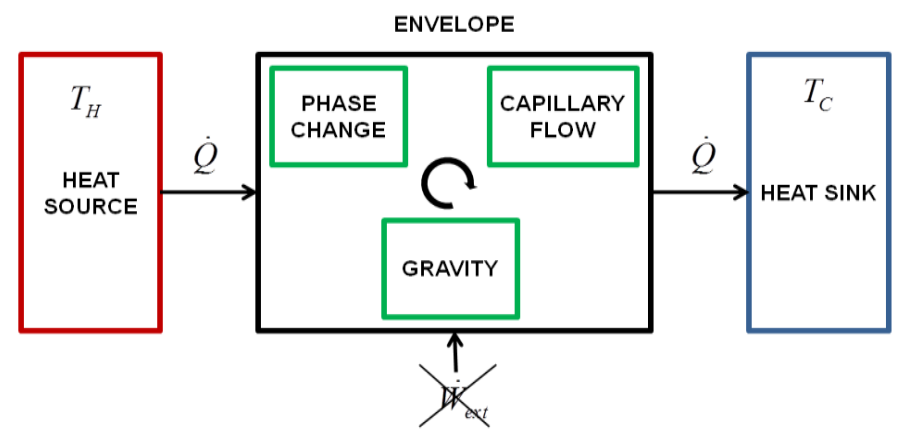

Fig. 1. General diagram of a passive heat exchanger [13].

An interesting classification of passive heat exchangers (Fig. 2) has been proposed by Khandekar and Groll [4]. 

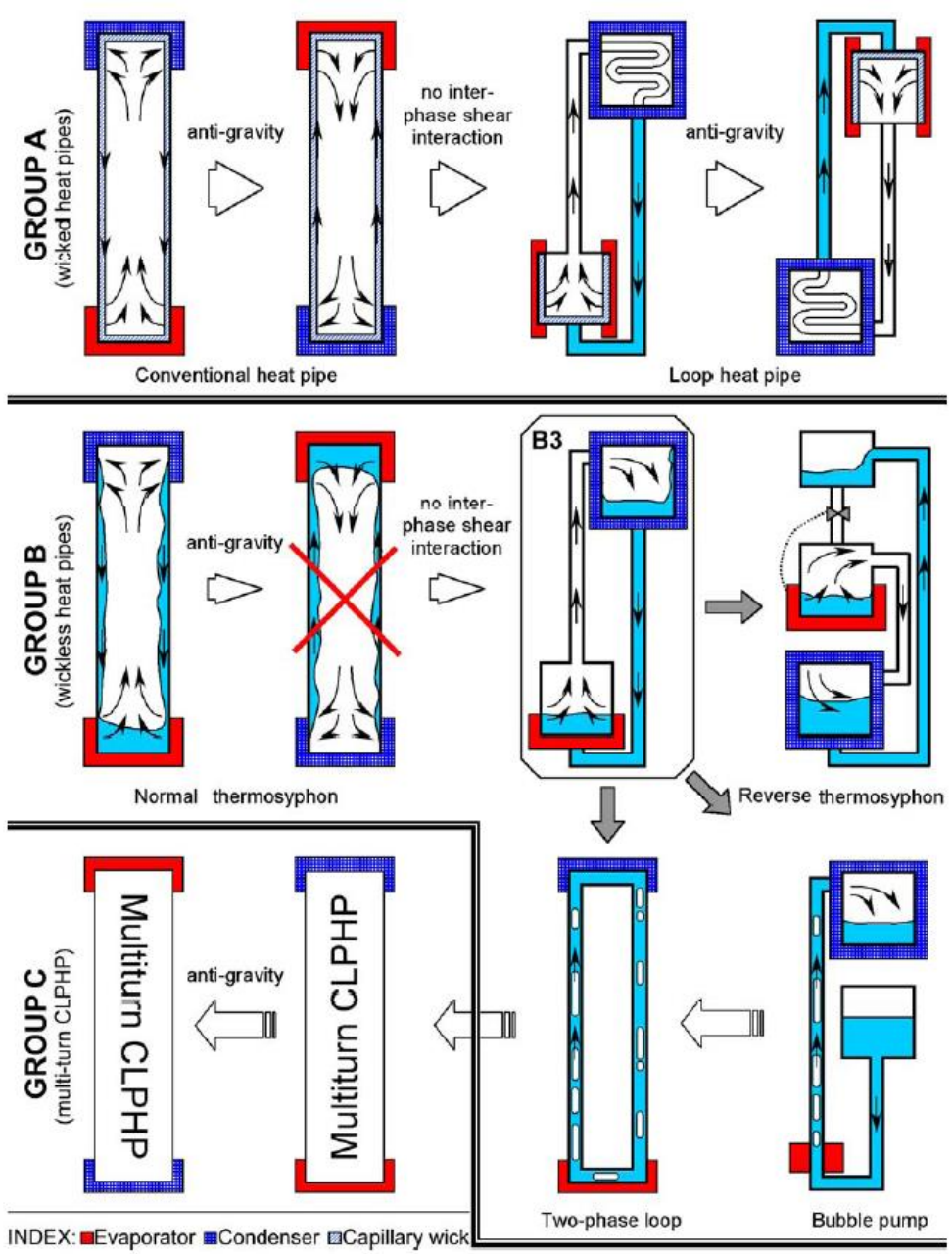

Fig. 2. Classification of passive heat exchangers proposed by Khandekar and Groll [4].

The proposed classification does not account for all existing systems. Group A includes systems where porous materials have been applied to transport condensate. In these devices, heat can be transferred by natural convection or against gravity. Group B devices are thermosiphons where porous materials are not used and where heat is transferred by free convection (force of gravity). This group includes anti-gravity thermosiphons with heat pipes that contain both liquid and vapor as well as loop thermosiphons where liquid and vapor travel through separate lines. Loop thermosiphons where heat is transferred against gravity are known as reverse thermosiphons. These devices require an additional liquid tank (reservoir) and a control valve.

Group C includes closed-loop pulsating heat pipes (CLPHP) where heat can be transferred by natural convection as well as against gravity.

\section{Reverse thermosiphon}

A reverse thermosiphon (RT) enables passive heat transfer in a direction opposite to natural convection (downward). One of the first devices of the type was developed by Tamburini in 1977. The proposed solution was used to cool electronic systems [14]. 
Depending on the applied solution, heat is transferred by:

- a gaseous medium (vapor),

- a liquid medium.

\subsection{Reverse thermosiphons with a vapor lift pump and one working medium}

Reverse thermosiphons rely on a vapor lift pump, also known as a bubble pump, to transfer heat downward from the tank. These devices are filled with one working medium. Their main advantage is a relatively simple structure and the absence of moving elements. A diagram of a solar heater with a vapor lift pump is presented in Figure 3.

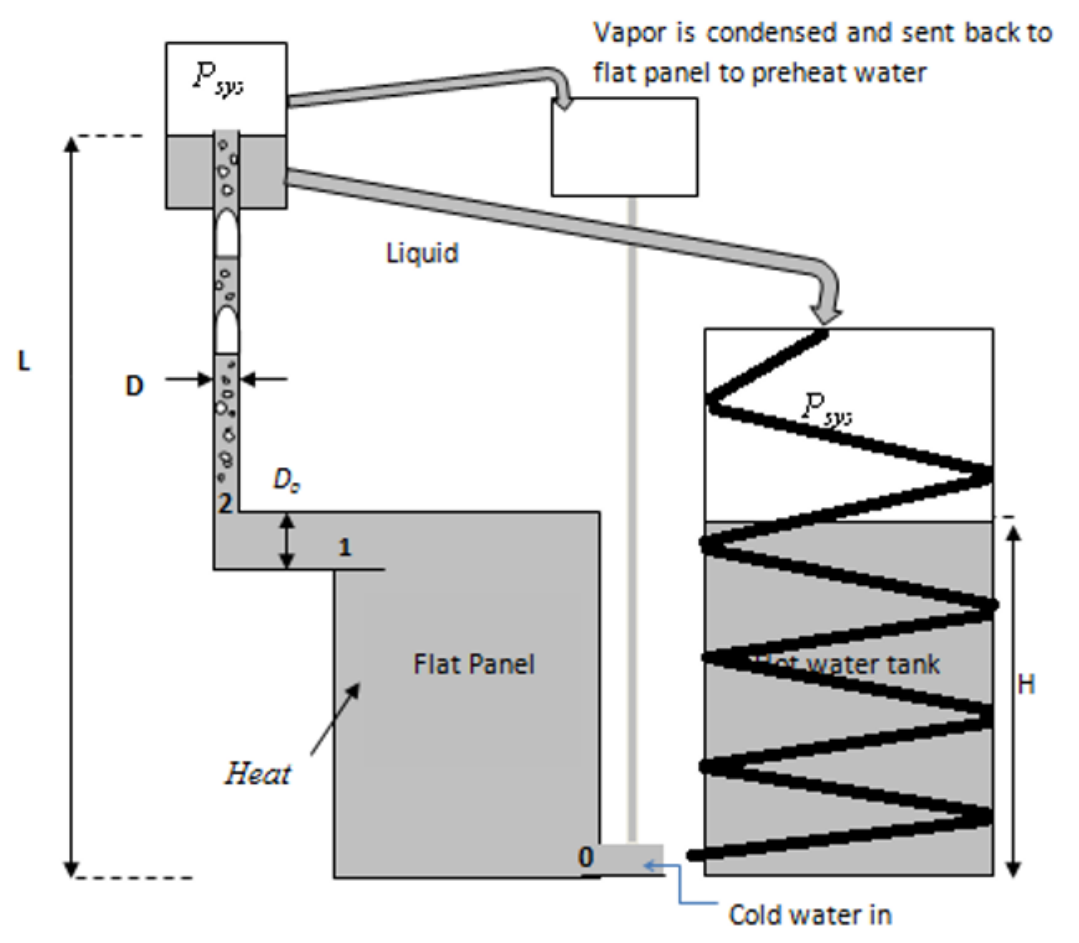

Fig. 3. Diagram of a solar heater with a vapor lift pump [15].

In this system, heat is transferred by a liquid medium. The heated medium is lifted by gas bubbles to the separator, and it returns to the hot water tank and the flat panel by force of gravity. The two-phase (liquid-vapor) reservoir is referred to as the bubble pump.

A system with a vapor lift pump and a solar collector was analyzed by Han-shik et al. [16]. This system was filled with water as the working medium for transporting heat from vacuum tube collectors. The tested installation had the height of $1 \mathrm{~m}$ and $5 \mathrm{~m}$. The device was activated when temperature inside the collector reached $90-100^{\circ} \mathrm{C}$. The experiment was conducted in a real-world setting, and the operation of the tested device was considerably influenced by variations in solar radiation. According to the authors, the developed device can replace an electric circulator pump. The discussed system is presented in Figure 4. 


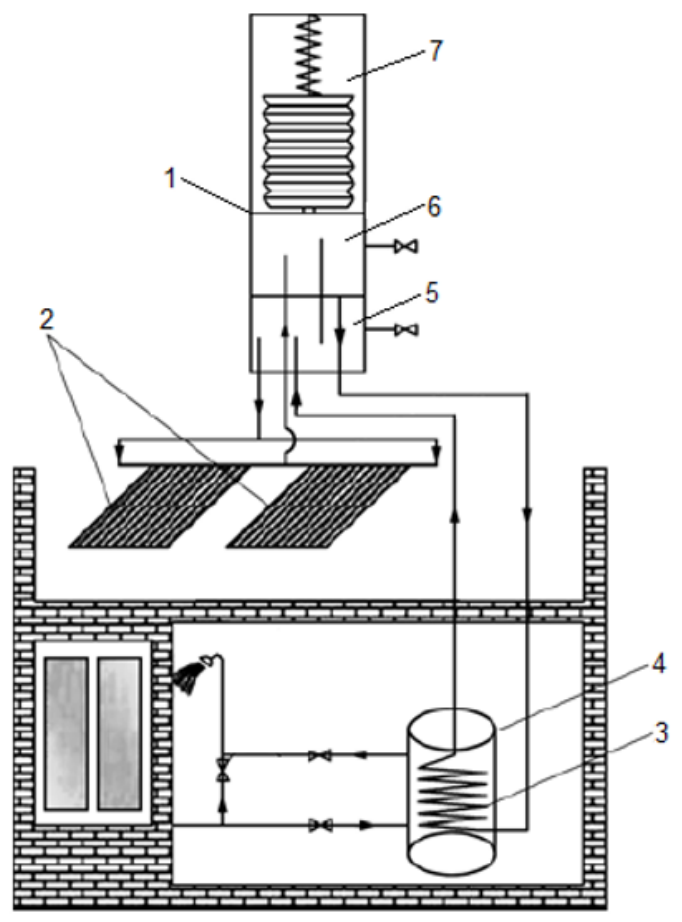

Fig. 4. Diagram of a heat exchanger with a vapor lift pump: 1 - bubble pump, 2 - solar collector, 3 heat exchanger, 4 - storage tank, 5 - condenser, 6 - separator, 7 - expansion chamber [15].

Similar systems that are filled with one working medium and use a vapor lift pump to transfer heat downwards have been analyzed by Ishizuka et al. [17], Ito et al. [18] and Yandri et al. [19].

\subsection{Conceptual diagram and the operating principle of a reverse thermosiphon with a vapor lift pump and two working media}

In the literature, all reverse thermosiphons with two-phase flow feature one working medium. A reverse thermosiphon with two mutually insoluble working media was developed in this study. In the proposed solution, working media do not come into direct contact and have different boiling points and density. The liquid medium is water and the pumping medium is hydrocarbon $(100 \mathrm{~g})$. The developed system is presented in Figure 5.

The device comprises a vapor lift pump, an evaporator, a separator, a condenser and a storage tank. The heat flux reaches the evaporator which is partly filled with the liquid medium (water). A thin layer of the pumping medium (3-12 $\mathrm{mm}$ ) with lower density floats on water. The liquid medium is heated, which raises the temperature of the pumping medium. When the vaporized pumping medium reaches the required pressure, it is transferred to the vapor lift pump via a dedicated channel. As a result, two-phase flow (liquid medium - vaporized pumping medium) takes place in the vapor lift pump, and the liquid medium is pumped to the separator. The liquid medium and the vaporized pumping medium are separated in the separator. Gravity drives the liquid medium to the storage tank. The liquid medium is cooled and recirculated to the evaporator. The vaporized pumping medium flows to the condenser, and the condensate returns to the evaporator by force of gravity. The system operates continuously when the heat flux reaching the device is constant and sufficient to vaporize the pumping medium. 


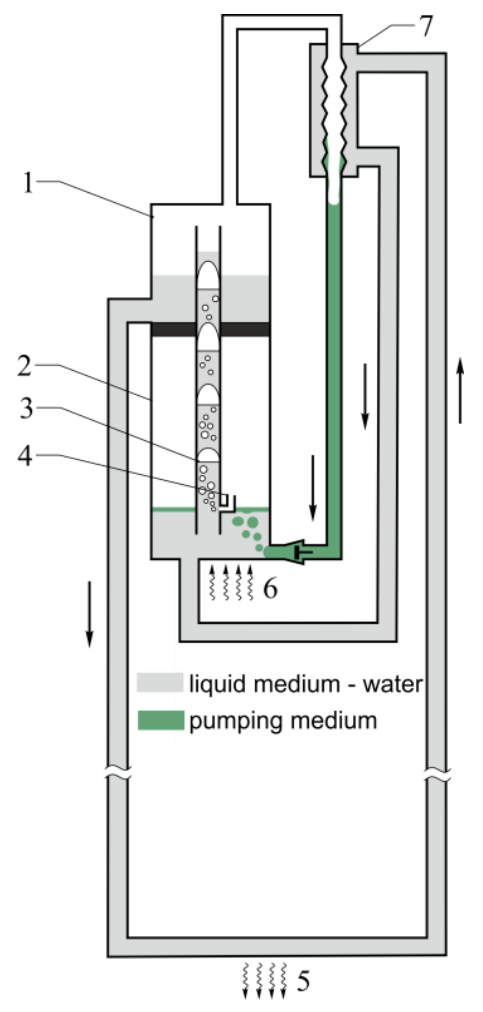

Fig. 5. Conceptual diagram of a reverse thermosiphon with a bubble pump and two working media: 1 - separator, 2 - evaporator, 3 - vapor lift pump, 4 - vapor channel, 5 - storage tank, 6 - heat flux, 7 condenser [20].

A solar collector can be used as a heat source in the proposed thermosiphon. Similarly to Figure 4, the heat exchanger is positioned above the solar collector.

\section{Conclusions}

Passive downward heat exchangers have been extensively investigated and described in the literature, but they are rarely used in practice. The above does not result from the lack of demand for such solutions, but from their weaknesses and limitations, including:

- the use of water as the working medium. When the temperature of the heat source drops below $100^{\circ} \mathrm{C}$, negative pressure is created, which compromises the system's tightness. Additional systems are required to maintain negative pressure,

- the use of a cooling medium. Positive pressure is maintained in the system when the temperature drops below $100^{\circ} \mathrm{C}$, but large amounts of coolant are required, which increases cost and exerts a negative impact on the environment,

- systems that operate cyclically with two working media require control valves, which contributes to the system's complexity and compromises reliability.

Further research is required to develop new solutions that are free of the above defects. The combination of a lift pump and two mutually insoluble media is a simple and reliable solution that could substantially improve the performance of the existing systems and increase the applicability of thermosiphon solar collectors. 


\section{References}

1. B. Kołodziej, M. Matyka. Odnawialne źródła energii, (Poznań 2012).

2. C. Charles, Jr., Roberts, J. of Heat Recovery Sys., 1 (4), 261 (1981)

3. Y. Dobriansky, Energy Conversion and Management, 52 (1), 414 (2011).

4. S. Khandekar, M. Groll,. 9th I. Heat Pipe Symposium, Malaysia (2008)

5. A. Faghri, Heat pipe science and technology, (Taylor \& Francis, 1995)

6. Y. Dobriansky, Tummavuoren Kirjapaino Oy, Espoo-Otaniemi, FIN (1997)

7. Y. Dobriansky, Y. Yohanis, A. of Thermodynamics, 31 (1), 32 (2010)

8. S. Filippeschi, I. J. of Thermal Sciences, 45 (2), 124 (2006)

9. Y. Koito, M. S. Ahamed, S. H. Harada, H. I. Imura, Applied Thermal Engineering, 29, 259 (2008).

10. Y. Koito, Y. Ikemizu, T. Tomimura, M. Mochizuki, Frontiers in Heat Pipes, 1 (1), (2010)

11. D. Chludzinski, J. Dobrianski, M. Duda, J. Piechocki, M. Samsel, R.Wojcik, Patents WO2012/015321A3 (2012)

12. M. Duda, University of Warmia and Mazury in Olsztyn, PhD Thesis (2012)

13. M. Mameli, Universita Degli Studi Di Bergamo, PhD Thesis (Bergamo 2012)

14. S. Filippeschi, E. Latrofa, G. Salvadori, 3rd I. S. on Two-Phase Flow Modelling and Experimentation, Pisa (2004).

15. Q. Zhang, S. W. Stewart, J. R. S. Brownson, L. T. Witmer, WREF 2012, World Renewable Energy Congress XII and (CRES), 613 (2012).

16. C. Han-shik, W. Ju-sik, S. Yong-han, K. Jun-hyo, J. Hyo-min, J. of Central South University, 19 (6), 1590 (2012)

17. T. Ishizuka, N. Miura, N. Yada, Studies of a top-heat-type thermosyphon. Kanagawa Institute of Technology, Japan.

18. S. Ito, K. Tateishi, N. Miura,. P. of ISES World Congress, 930 (2007)

19. E. Yandri, N. Miura, T. Kawashima, T. Fujisawa, M. Yoshinaga, ISES-AP - 3rd I. Solar Energy Society Conference, Sydney (2008).

20. J. Dobrianski, D. Chludzinski, M. Duda, A. Błaszczyk, Patents PL227757, (2018) 